\title{
Inventory Simulation Model of a Lamp of Maintenance Warehouse of Facilities Management Department at Southeast Missouri State University Using Arena
}

\author{
Muhammad Abdus Samad*, Vijay Anand \\ Department of Polytechnic Studies, Southeast Missouri State University, USA
}

Copyright $\bigcirc 2016$ by authors, all rights reserved. Authors agree that this article remains permanently open access under the terms of the Creative Commons Attribution License 4.0 International License

\begin{abstract}
It has been observed that inventory problems related to too small or very large order quantities may be the reason of failure in business. Optimal inventory management is very essential in order to reduce cost, stock out and meet the uncertain demand continuously. This simulation is done over a maintenance warehouse of facilities management department at Southeast Missouri State University. The problem addressed in this study is the lack of proper inventory management is the reason for excessive cost in the maintenance warehouse of facilities management department at Southeast Missouri State University. Sometimes stock out of lamp occurs which cost extra money due to urgent order made. The purpose of this study is to develop an inventory model of a lamp that will optimize the inventory level and minimize cost and stock out of this lamp of the maintenance warehouse of facilities management department at Southeast Missouri State University, and at the same time meet the uncertain needs or demands of the different departments that arise randomly throughout the year.
\end{abstract}

Keywords Inventory Management, Simulation, Inventory Model, Arena

\section{I .Introduction}

Inventory management is very important for any organization to meet uncertain needs or demand of the users or customers. In order to gain advantages in supply chain management, how to keep inventory in adequate level and how to enhance customer service level are two critical practices for decision makers in today's world [1]. Inventory means storing items in the warehouse so that it can be used when needed. Inventory is the physical storage of products or items in the warehouse so that the company or organization can maintain efficient and uniform flow of their operations without being interrupted. Inventory management has received great attention in a way that researchers have been focusing on study of inventory management in presence of supply chain problems, like supply disruption [2]. Literature that represents the inventory management with respect to supply disruption includes [3-5]. If inventory level is very high, holding cost will be increased. On the other hand, if inventory level is kept low, the number of orders per year will be increased and hence ordering cost will be increased as well. Hence, there should be an optimal inventory level that will minimize the total annual carrying and ordering cost and at the same time minimize cost and meet uncertain demand. Lack of proper inventory management is the reason for excessive cost of any sort of business organization. Therefore, managers of any business organization should be much concerned about proper inventory management to minimize the cost of inventory. It is the job of the inventory manager to determine an appropriate inventory level that will balance the costs and pressures, which argue for both high and low inventories [6]. The manager is cost conscious and wants economically manage the inventory, for example, timing and quantity of ordering the products [7]. The important terminology in the inventory management system includes: target stock level, demand in a given time frame, lead time, order quantity, and reorder point. The demand is measured in terms of quantities needed by customers or users in a given time period. It is usually very hard to predict and stochastic [8]. Lead time is the time between placing and receiving an order. Due to the uncertainty of demand of the product and the uncertainty of lead time to get a product from supplier, stock out occurs, which results in dissatisfaction of the users. A stock out is very expensive due to the urgent order made or backorder cost, lost sales and customers who are lost [9]. This research work is done over a maintenance warehouse of facilities management department at Southeast Missouri State University. The present paper includes the problem that is addressed, high level overview and a description of the maintenance warehouse of facilities management department, source of randomness, arena simulation for the inventory of a lamp of the maintenance 
warehouse of facilities management department, results, data analysis, and optimization process of the lamp.

\section{The Problem}

\section{A. Problem}

The problem addressed in this study is the lack of proper inventory management is the reason for excessive cost in the maintenance warehouse of facilities management department at Southeast Missouri State University. Sometimes stock out of lamp occurs which cost extra money due to urgent order made.

\section{B. Layout of the Maintenance Warehouse of Facilities Management Department}

Maintenance Warehouse of Facilities Management Department stores inventory for the Southeast Missouri State University. The process starts when problems arise in any department that triggers administration of that department to send demand or issue a work order to facilities management department. Then, facilities management department send maintenance technician to look at the problem. After looking at the problem, if maintenance department can fix the problem, they send demand order for the item or product to the maintenance warehouse. If parts are available, it is supplied by the maintenance warehouse department. If parts are not available, maintenance warehouse send order to outside source and received order and finally meets demand for the part. On the other hand, if maintenance department cannot fix the problem, they let the concerned department to buy a new one. The high level layout of the Maintenance warehouse of facilities management department is shown figure 1.

\section{High Level Overview}

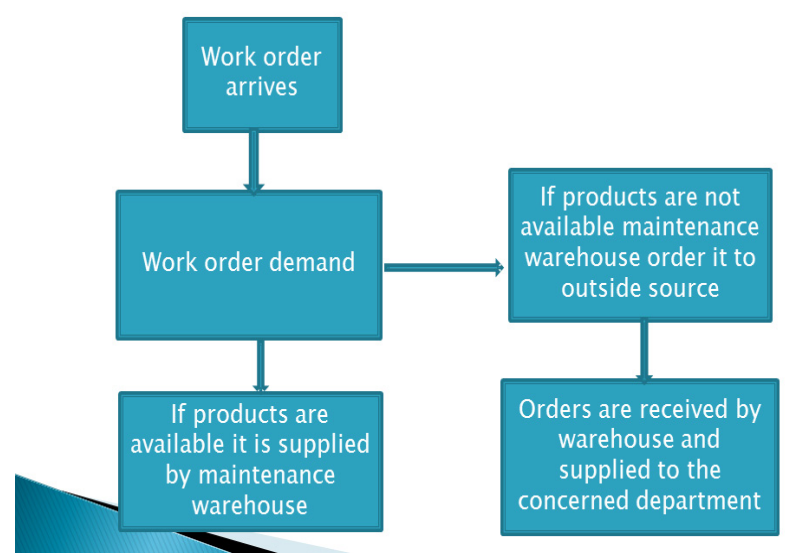

Figure 1. High level overview

\section{Source of Randomness}

The source of randomness for this study is the demand for the lamps or inventory that comes from the various departments throughout the year. Another source of randomness is lead time of the purchase order. Lead time is the time between placing an order and receiving it. Whenever maintenance warehouse place an order to outside supplier, it takes approximately ten to fourteen days to receive this order. Sometimes this lead time fluctuates which is the main cause of stock out of inventory.

Data has been collected from the maintenance warehouse of facilities management department at Southeast Missouri State University. The maintenance warehouse is storing inventory of 9500 different products or items out of which 200 are various types of lamps. For this project a particular type of inventory of Lamp, Fluorescent, F32T8/T1741/Alto is selected to optimize its inventory level using arena simulation software.

\section{Arena Model}

Arena is automation software which is developed by system modeling. In arena, by placing the modules (boxes with different shapes) that represent different process with logistics, people can simulate data in order to get desired output. Every box or module is connected with line that indicates the physical flow path of entity [10].

We are using the student version of arena which is free software with limited events. In order to get the desired output, this arena simulation software will be feasible for my inventory simulation study [11].

By running an inventory simulation model and using process analyzer it will be possible to find out several scenarios and from which the best scenario that will optimize the inventory level, meet demand, as well as minimize stock out and cost.

\section{A. Design}

Design is created considering work order that arrives from different department to the maintenance warehouse of facilities management department. Then the demand of each work order is recorded and met by the maintenance warehouse. When the inventory level is reached to a predetermined level called reorder point, a new purchase order of the product is sent to the outside supplier. It takes 10 to 14 days to receive a purchase order from the supplier. Sometimes the purchase order makes delay and stock out occurs. Sequence is connected with lines which represents the flow of entity. Maintenance warehouse demand fulfillment and inventory fulfillment flow design is shown below in figure 2 (simulation mode) and in figure 3 (running mode). 
Order Fulfillment

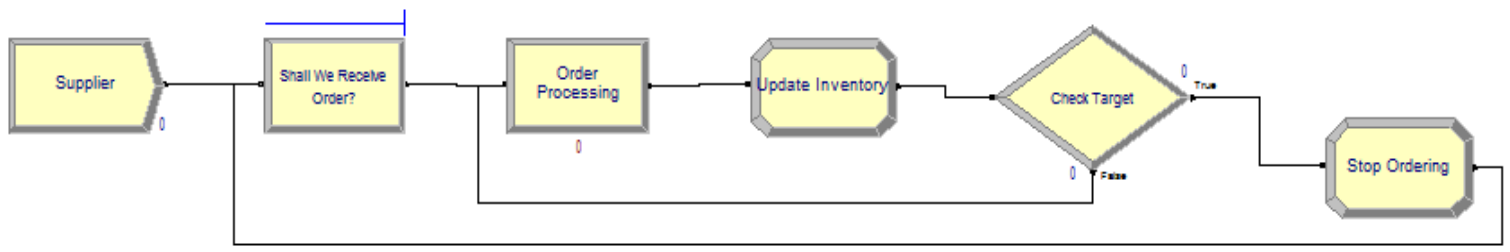

Demand Fulfillment

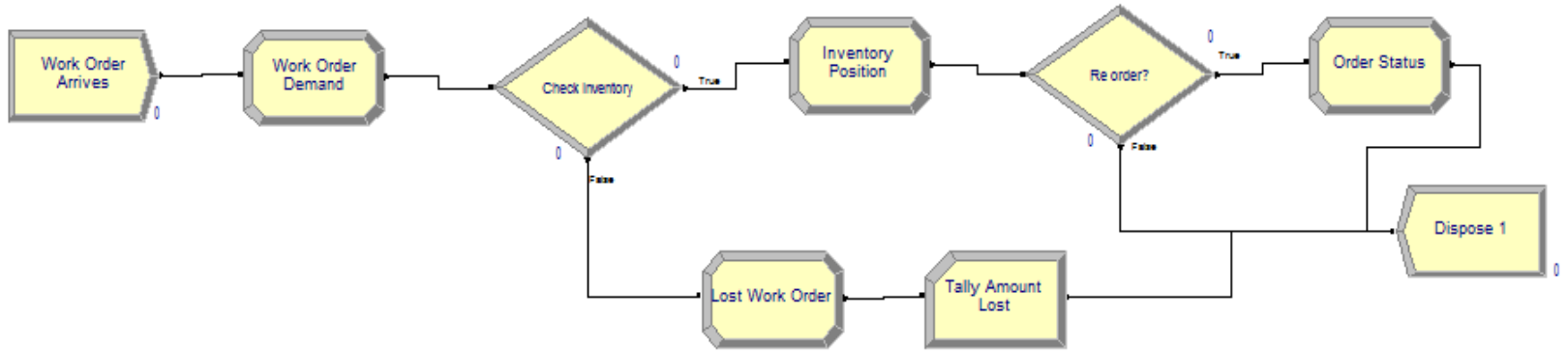

Figure 2. (Simulation Mode)

Order Fulfillment

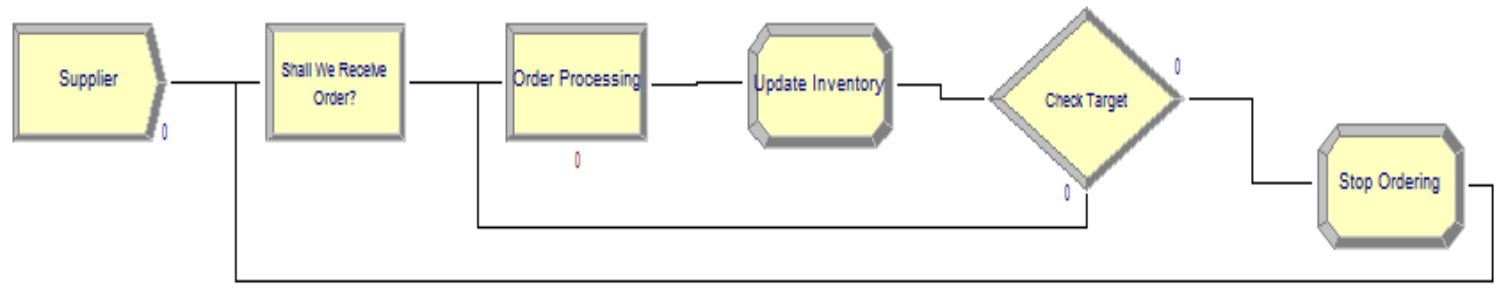

Demand Fulfillment

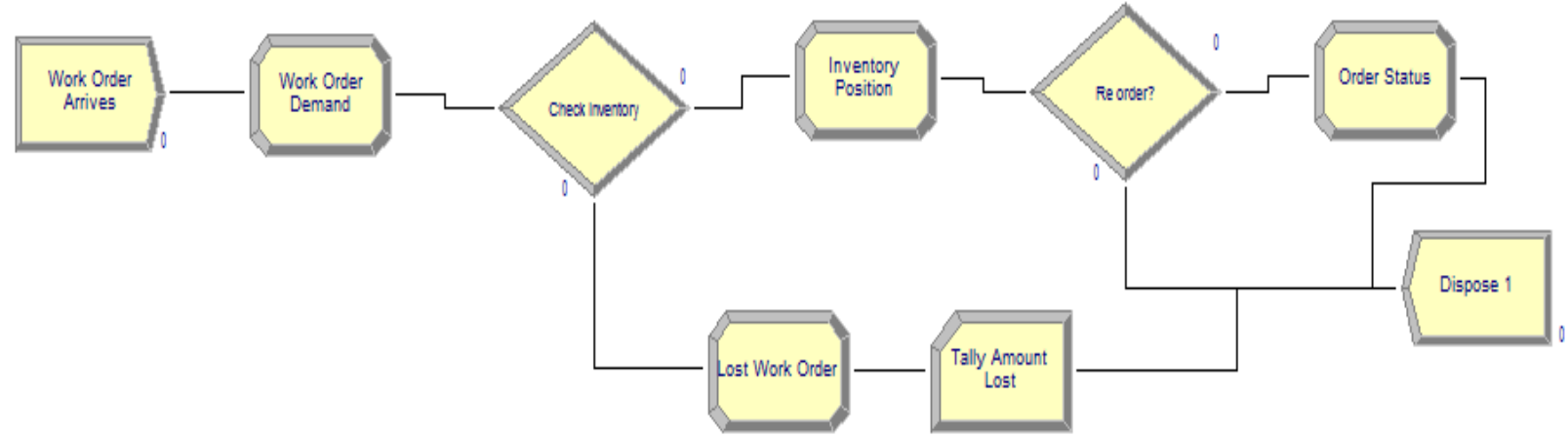

iress F1

Figure 3. (Running Mode)

\section{B. Data collection and Input Analyzer}

Data have been collected from the maintenance warehouse of facilities management department at Southeast Missouri State University. The work order that arrives from various departments and demand that is being verified by the maintenance technician is recorded by the maintenance warehouse and is used in this simulation model. The purchase order quantity or batch size, reorder point, and 
target stock of this lamp that had been using by the maintenance warehouse has been used in this simulation model.

Normally the warehouse place purchase order to outside supplier when the inventory level reaches to reorder point and demand is higher than on hand inventory during the lead time of purchase order, stock out occurs. It also occurs when order makes delay to receive. During stock out, for emergency work order they pay extra money to supplier in order to receive the product urgently. But in case of non-emergency work order they make the concerned department to wait until their purchase order is received. Hence, when stock out occurs, maintenance warehouse has to spend extra money. Data for work order that arrives to maintenance warehouse has been analyzed by using the Input Analyzer. After verifying the quantity demanded by the each work order by the maintenance technician, demand quantity has been analyzed by using the Input Analyzer. Work order data analyzer is shown in figure 4 and demand for the product data analyzer is shown in figure 5 . From the Input Analyzer it has been observed that the arrival of work order follows Beta distribution and quantity demanded by each work order which is verified by the maintenance technician follows exponential distribution. After placing the data into Input Analyzer and running it, we observed several distributions and among them we selected the above distributions as these distributions make minimum error. The two expressions generated from the distributions have been used in the inventory simulation model with arena and are shown in the figures 4 and 5 below.

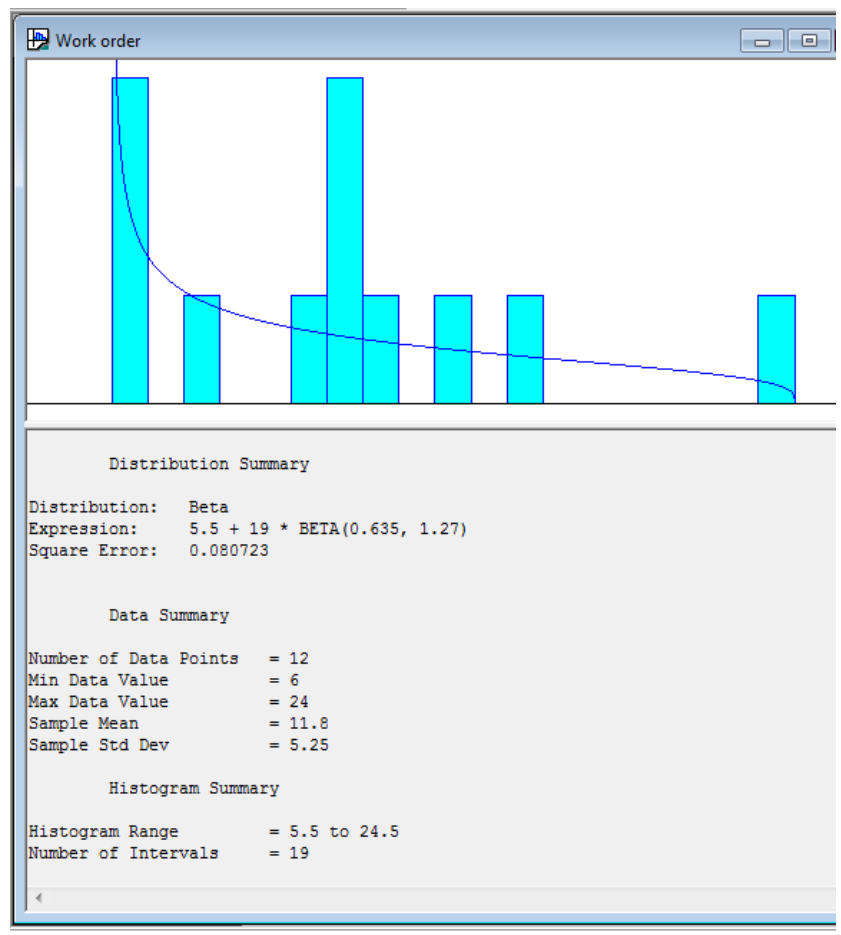

Figure 4. (Work Order data analyzer)

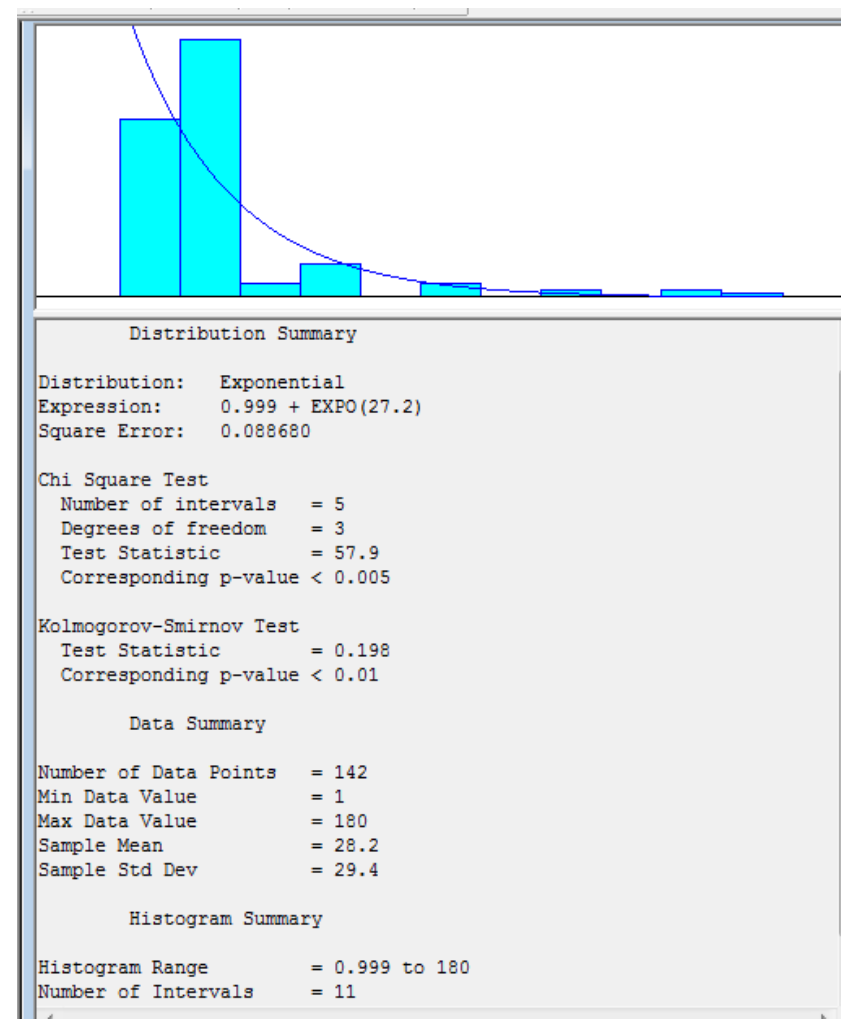

Figure 5. (Demand for Product data analyzer)

The expression for Beta distribution is $5.5+19 *$ BETA $(0.635,1.27)$ and the expression for Exponential distribution is 0.999 + EXPO (27.2) have been used in the simulation study. We have generated 100 replications of the simulation for 10,000 hours. After running the simulation, the results that we got is shown in the following figure 6 .

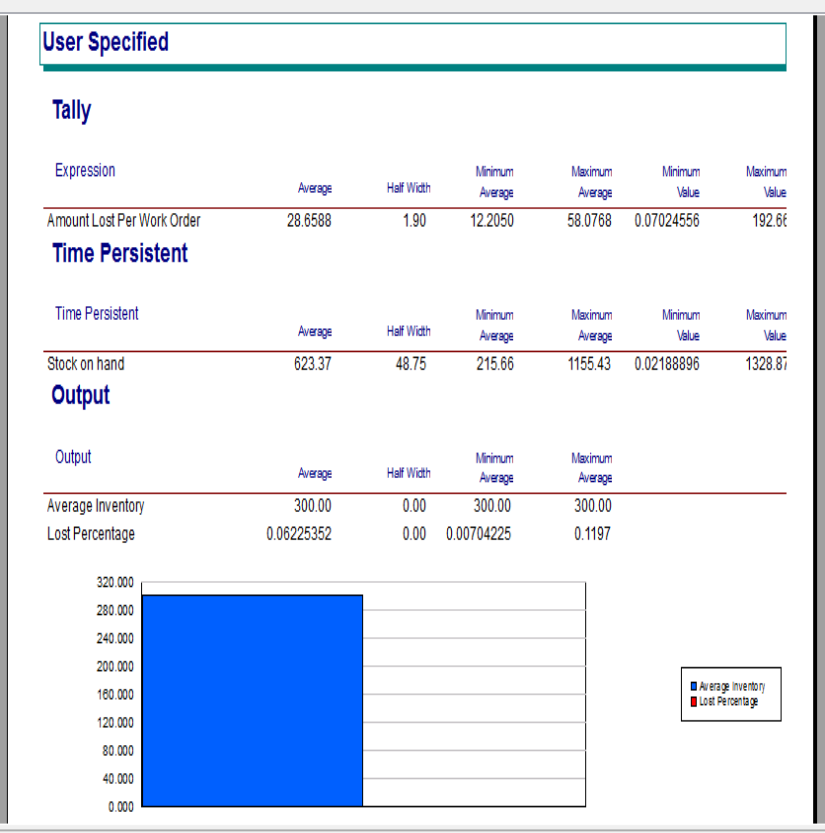

$100 / 100 \quad(10000.0000$ Hours $)$ Saturday, May 19,2018

Figure 6. (Results) 
Results shows that the percentage of lost work order is $6.22 \%(0.06225352 * 100)$ and the amount lost per work order is 28.6588 units. Results also shows that the stock on hand is 623.37 units and average inventory is 300 units.

\section{Output Analyzer}

The data that have been collected from maintenance warehouse of facilities management department is used for output analysis. The critical part of this simulation model is lost work order and the percentage of lost work order has been analyzed in the output analyzer. Histogram for lost work order is shown in the following figure 7. From the histogram it is clearly seen that 1 percent of replication shows that the los work order is between 1 and 2 percent. 17.17 percent replication shows that lost work order is between 4 and 5 percent. Another 18.18 percent replication (which is the highest percentage of replication) shows that lost work order lies between 7 and 8 percent.

Analysis of $95 \%$ confidence interval has been created by using output analyzer and is shown in figure 8. Average value of this interval is $6.23 \%$. Standard deviation is 0.0242 . Minimum and maximum value of this interval is $0.7 \%$ and $12 \%$ respectively. Hence $95 \%$ confidence interval indicates that the lost work order percentage lies between $0.7 \%$ and $12 \%$.

Another figure that has been created by using the output analyzer is Plot-lost percentage which is shown in the figure 9 below.

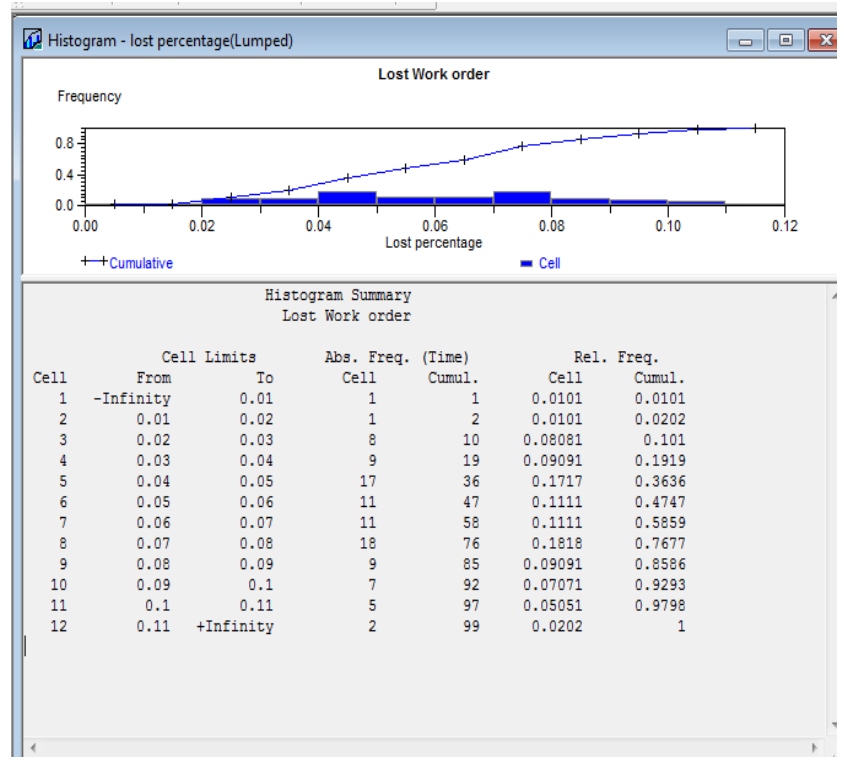

Figure 7. (Lost Work Order Percentage)

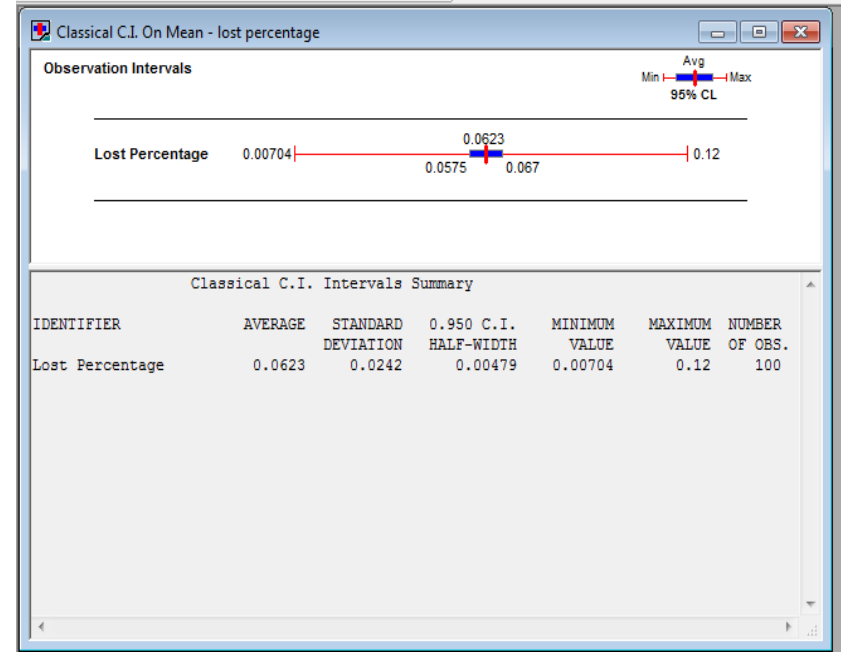

Figure 8. ( $95 \%$ Confidence Interval for Lost Work Order)

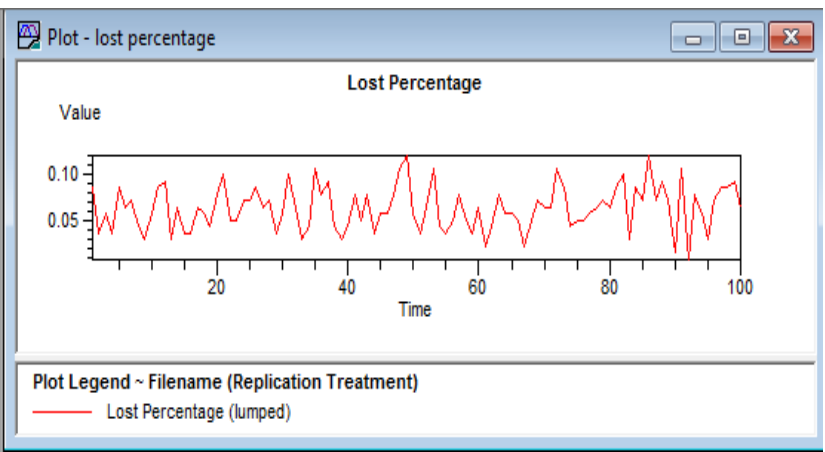

Figure 9. ( Plot- Lost Percentage)

\section{Process Analyzer}

Process analyzer is used in order to optimize a process. Data have been simulated in the process analyzer in order to get the best scenario of the inventory model which optimizes the inventory level and reduce stock out and cost. Here 14 scenarios have been generated by varying the controls such as batch size, reorder point, and target stock to get the response such as lost work order, lost percentage of work order, amount lost per work order, and final inventory. Scenario 1 is the present scenario of the maintenance warehouse. In this scenario, batch size is 600 units, reorder point 150 units, and target stock is 750 units. The response are- lost work order is 8.84 , lost percentage of work order is 6.2 , amount lost per work order is 28.66 , and final inventory is 661.63 units. Among the fourteen scenarios it is found that the best scenario is scenario 4 . In scenario 4 , it is clearly evident that if the batch size is 650 units, reorder level is 350 units, and target stock is 900 units; then lost work order is less than a unit ( 0.87 unit) and the lost percentage of work order is 0.6 , amount lost per work order is zero units, as well as final inventory is 825.73 units. 


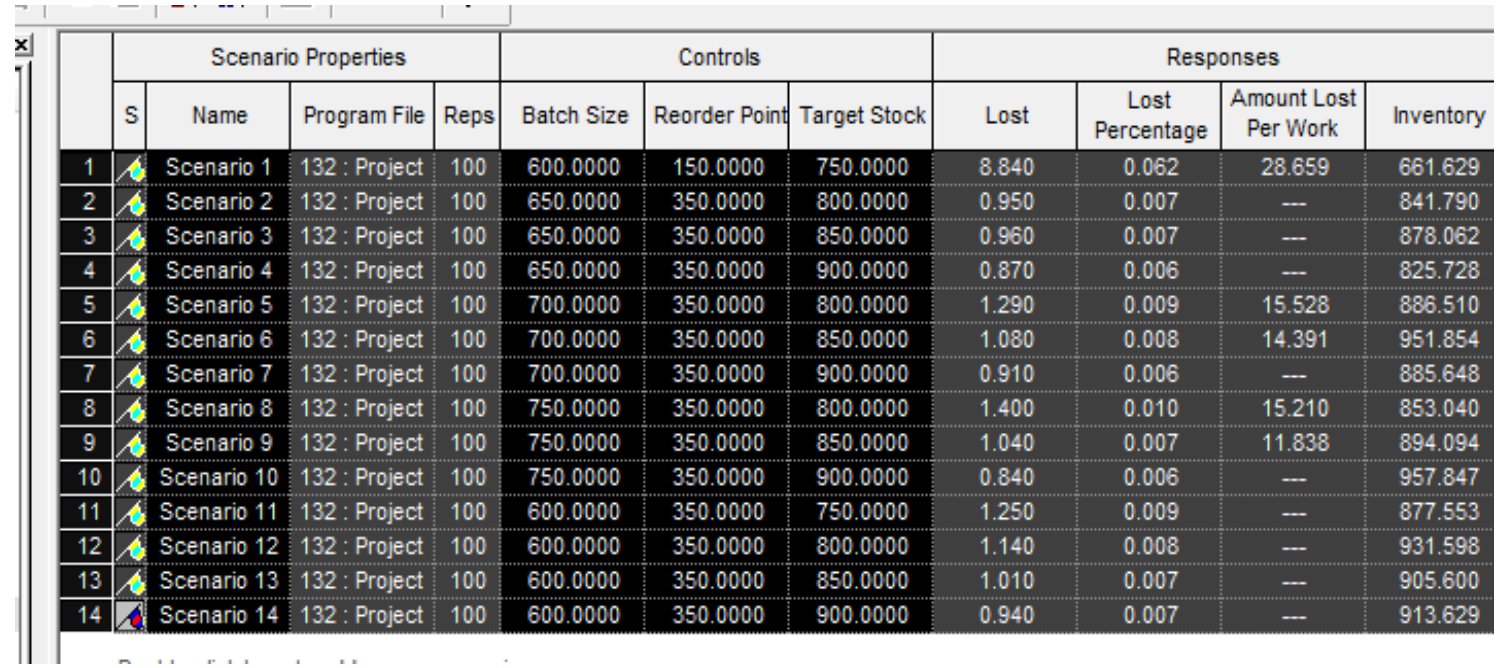

Figure10. (Optimization Process)

\section{Conclusions}

At present it is seen from the result that the lost work order of maintenance warehouse is 6.2 percent. From the process analyzer or optimization process it is found that the maintenance warehouse should use a batch size of 650 units, reorder point of 350 units, and target stock of 900 units to minimize cost and stock out of this lamp. This will result in 0.6 percent of work order lost and the amount lost per work order is zero. This result indicates an improvement of 90.32 percent of the lost work order of the lamp. Hence, in order to meet uncertain demand and reduce stock out and cost, maintenance warehouse should have target stock of 900 units of this lamp and order a batch size of 650 units at a reorder point of 350 units.

\section{Future Work}

Consideration of safety stock should be included in arena model of this lamp to minimize stock out or lost work order. Simulation study should also be done on all other types of lamps in the maintenance warehouse to optimize their inventory level, minimize cost, and to reduce stock out as well as to maintain smooth functioning of various departments of Southeast Missouri State University. Apart from lamps all other inventory items of the maintenance warehouse should be simulated to optimize their inventory level and to minimize cost and stock out.

\section{Acknowledgement}

I would like express my heartiest thanks to Dr. Vijay Anand who help me continuously throughout the course to do this simulation. I also would like to thanks to Mark E. Masters, maintenance warehouse in charge, for helping me understanding the process and providing the data. Finally, Arena simulation software team gives us the opportunity to use free student version simulation software in order to run a smaller simulation for research project.

\section{REFERENCES}

[1] Yang, Ming-Feng; Lin, Yi; Ho, Li Hsing; and Kao, Wei Feng (2016). An Integrated Multiechelon Logistics Model with Uncertain Delivery Lead Time and Quality Unreliability. Mathematical Problems in Engineering. Vol.2016, pp 1-13. DOI: $10.1155 / 2016 / 8494268$

[2] Azimi, Parham; Reza Ghanbari, Mohammad; and Mohammadi, Hasan (2012). Simulation Modeling for Analysis of a (Q, r) Inventory System under Supply Disruption and Customer Differentiation with Partial Backordering, Modelling and Simulation in Engineering. Vol 2012, pp 1-10. DOI:10.1155/2012/103258.

[3] H. P. Chao (1987). Inventory policy in the presence of market disruptions. Operations Research, Vol. 35, No. 2, pp. 274-281.

[4] J. S. Song and P. H. Zipkin (1996). Inventory control with information about supply conditions. Management Science, Vol. 42, No. 10, pp. 1409-1419.

[5] B. Lewis, Inventory control with risk of major supply chain disruptions, Ph.D. thesis, Georgia Institute of Technology, 2005.

[6] Raida Abuizam (2011). "Optimization of (s,S) periodic review inventory model with uncertain demand and lead time using simulation". International Journal of Management and Information Systems: First Quarter, Vol. 15, No. 1, pp 67-79.

[7] Jian Zhang and Bonnie Tom (2009). Application of computer simulation software to operation and inventory managementA Case Study. International Journal of Organizational Innovation

(online), Vol 1 No. 3, pp 66-85. http://international.vlex.com /vid/computer-software-management-case-study-227790499.

[8] B. Knezevic (2011). "Usage of simulation in inventory management education”. Annals \& Proceedings of DAAAM 
International, Vol. 22, No. 1, pp 1197-1198, 2011.

[9] J.R. Tony Arnold,Stephen N. Chapman, and Lioyld M. Clive (2012). Introduction to Materials Management. Chain, Pearson Education Asia Ltd., 2013, pp. 200-203.

[10] Tayfur Altiok and Benjamin Melamed. Simulation Modeling and Analysis with Arena. USA, Elsevier, 2007, pp. 65-311.

[11] https://www.arenasimulation.com/industry-solutions/logistic s-simulation-software.

[12] Maintenance Warehouse, Facilities Management Department at Southeast Missouri State University. 